\title{
Performance of Sea Surface Salinity and Soil Moisture Retrieval Algorithms With Different Auxiliary Datasets in 2-D L-Band Aperture Synthesis Interferometric Radiometers
}

\author{
Adriano Camps, Senior Member, IEEE, Mercè Vall-1lossera, Member, IEEE, Núria Duffo, Member, IEEE, \\ Francesc Torres, Member, IEEE, and Ignasi Corbella, Member, IEEE
}

\begin{abstract}
The Soil Moisture and Ocean Salinity (SMOS) Earth Explorer Opportunity Mission was selected in May 1999 by the European Space Agency Earth Observation Programme Board to provide global and frequent soil moisture (SM) and sea surface salinity (SSS) maps. SMOS' single payload is the Microwave Imaging Radiometer by Aperture Synthesis (MIRAS) sensor, an L-band two-dimensional aperture synthesis interferometric radiometer with multiangular and polarimetric imaging capabilities. The definition of the SMOS Level 2 Processor requires the selection of the optimum operation mode (dual-polarization or full-polarimetric) for each application, the specification of the required auxiliary data, and the optimum retrieval algorithms. Using the SMOS simulator and based on the experience gained in previous works, this paper presents a study of the SM and SSS retrieval capabilities over homogeneous pixels, in the two modes of operation with different auxiliary data. It is found that SSS retrievals using the first Stokes parameter measured in the dual-polarization mode perform somewhat worse than using the vertical $\left(T_{\mathrm{vv}}\right)$ and horizontal $\left(T_{\mathrm{hh}}\right)$ brightness temperatures measured in the full-polarimetric mode, and the performance degrades for cold waters due to the lower sensitivity of the brightness temperature to SSS at low sea surface temperature (SST). Due to the larger angular variation of $T_{\mathrm{hh}}$ and $T_{\mathrm{vv}}, \mathrm{SM}$ retrievals using $T_{\mathrm{hh}}$ and $T_{\mathrm{vv}}$ measured in the full-polarimetric mode exhibit a significant better performance over bare soils than over vegetation-covered soils. Over vegetation-covered soils vegetation parameters (opacity and albedo) can be inferred over a 550- $\mathrm{km}$ swath width in the full-polarimetric mode. However, since the first Stokes parameter is independent of both geometric and Faraday rotations, it is very robust in the presence of instrumental and geophysical errors. In the SSS retrieval problem and in the SM retrieval problem (with $T_{\mathrm{hh}}$ and $T_{\mathrm{vv}}$ measured in the full-polarimetric mode), the performance of the retrieval algorithms tested is not significantly altered if the model parameters are not exactly known, but are left as adjustable parameters in the optimization process.
\end{abstract}

Index Terms-Aperture synthesis, L-band, ocean salinity, radiometry, retrieval, soil moisture.

Manuscript received May 9, 2004; revised November 14, 2004. This work was supported in part by the Spanish Comisión Interministerial de Ciencia y Tecnología under Grant MCYT TIC2002-04451-C02-01) and in part by the Spanish Space National Plan under Grant ESP2002-11648-E: "MIDAS-2: Definición del proceso de datos de la misión espacial SMOS en la estación de Villafranca del Castillo (SMOS-GS-B)."

The authors are with the Department of Signal Theory and Communications, Universitat Politècnica de Catalunya, E-08034 Barcelona, Spain (e-mail: camps@tsc.upc.edu).

Digital Object Identifier 10.1109/TGRS.2004.842096
TABLE I

Main SCIENTIFIC ReQuirements of THE SMOS MisSion. SEE ALSO http://www.cesbio.ups-tlse.fr/data_all/pdf/SMOS_MRD_V5.pdf

\begin{tabular}{cl}
\hline Ocean: global Sea Surface Salinity maps & $0.1 \mathrm{psu}$ every 30 days \\
& $200 \mathrm{~km}$ spatial resolution \\
\hline Land: global Soil Moisture and & $0.04 \mathrm{~m}^{3} / \mathrm{m}^{3}(4 \%)$ every 3 days \\
vegetation water content maps & $0.2 \mathrm{~kg} / \mathrm{m}^{2}$ \\
& $<50 \mathrm{~km}$ spatial resolution \\
\hline Cryosphere (experimental): & Improved snow mantle monitoring and \\
& multilayer ice structure.
\end{tabular}

\section{INTRODUCTION}

$\mathbf{T}$ HE SCIENTIFIC requirements of the Soil Moisture and Ocean Salinity (SMOS) mission are listed in Table I. Microwave radiometry at L-band can achieve these requirements. However, real aperture radiometers require very large antennas $(\sim 4 \mathrm{~m})$ to achieve a moderate spatial resolution $(\sim 50 \mathrm{~km})$ from a low earth orbit. To overcome this problem, and reduce mass, SMOS makes use of two-dimensional (2-D) aperture synthesis interferometric radiometry techniques for the first time in earth observation from space. A synthetic aperture interferometric radiometer forms a brightness temperature image in the direction cosines domain $(\xi, \eta)=(\sin \theta \cos \varphi, \sin \theta \sin \varphi)$ by a Fourier synthesis technique of the cross correlations of the signals collected by each pair of receiving elements. In the Microwave Imaging Radiometer by Aperture Synthesis (MIRAS) sensor, the receiving elements are distributed along three arms $120^{\circ}$ apart, and they are spaced $d=0.875$ wavelengths (Fig. 1), producing an optimum hexagonal sampling of the Fourier domain [1]. However, since the Nyquist criterion for hexagonal sampling $(d=1 / \sqrt{3}$ wavelengths [1]) is not satisfied, the reconstructed 2-D brightness temperature image suffers from aliasing1 [Fig. 2(a)]: earth replicas or "aliases" overlap with the

\footnotetext{
${ }^{1}$ The antenna spacing $d=0.875$ wavelengths was selected to optimize the instrument's angular resolution, while keeping a swath wide enough so that the revisit time is satisfied.
} 


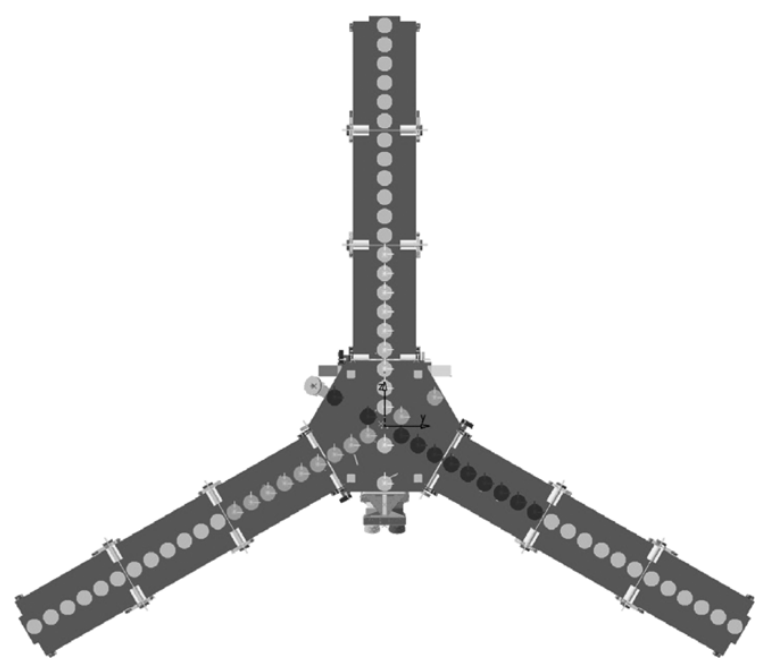

Fig. 1. SMOS payload module (MIRAS) phase B configuration (courtesy of EADS-CASA Espacio, Spain): Y array with 3 arms $120^{\circ}$ apart, with 21 light and cost effective front-ends (LICEFs), plus two redundant LICEFs per arm (one LICEF and one LICEF/NIR) in its opposite direction in the hub. Spacing between adjacent elements is 0.875 wavelengths.

earth image, determining the instrument's alias-free field of view (FOV). In the real situation, sophisticated image reconstruction algorithms [2], [3] are required to account for instrument imperfections and obtain the brightness temperature maps in the antenna reference frame (level $1 \mathrm{~b}$ data: $T_{\mathrm{xx}}$, $T_{\mathrm{yy}}$; Table II) from the calibrated observables (level 1a data; Table II).

The unique characteristics of the SMOS imaging configuration are as follows:

- 2-D imaging capabilities in dual- or full-polarization modes [4];

- multilook and multiangular imaging of each pixel as the satellite advances. In a series of consecutive snap-shots, pixels move from the top to the bottom of the alias-free FOV [vertical arrows in Fig. 2(b)], appearing in different positions and being observed under different incidence angles, with different spatial resolution and radiometric sensitivities.

\section{RETRIEVAL OF GEOPHySiCAL PARAMETERS: STATEMENT OF THE PROBLEM}

The geophysical parameter retrieval algorithms [level 2: soil moisture (SM) and ocean salinity (OS) retrieval; Table II] must then be tailored to take full advantage of the SMOS imaging characteristics and, in particular, to its multilook and multiangular imaging capabilities. In addition, since there is a single receiving unit per dual-polarization antenna, two modes of operation are foreseen in SMOS [4], which are summarized as follows.

- Full-polarimetric mode: In order to avoid image blurring, there are two alternate measurement cycles. During the odd periods $(2.4 \mathrm{~s}$ long) the antenna polarization switches are $1.2 \mathrm{~s}$ at $x$ polarization to obtain $T_{\mathrm{xx}}(\xi, \eta)$, and then: $0.4 \mathrm{~s}$ in the so-called $\alpha$-mode, $0.4 \mathrm{~s}$ in the

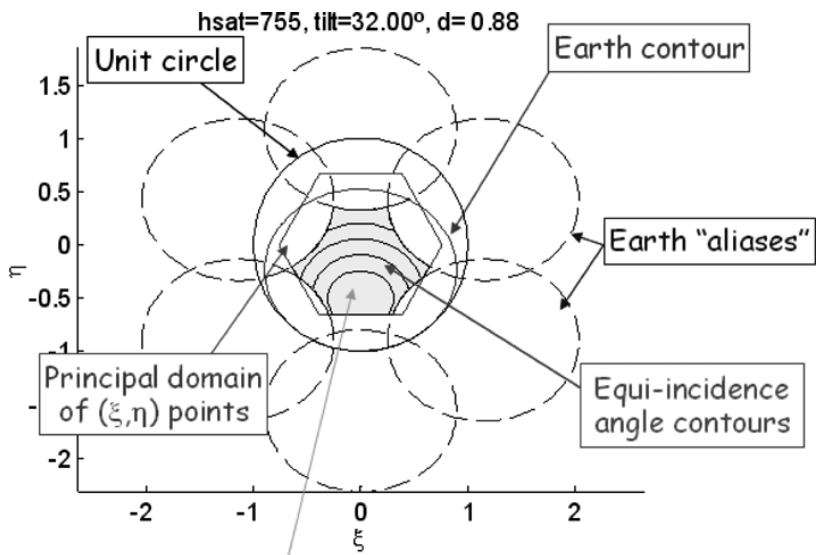

a)

\section{Alias-free Field Of View}

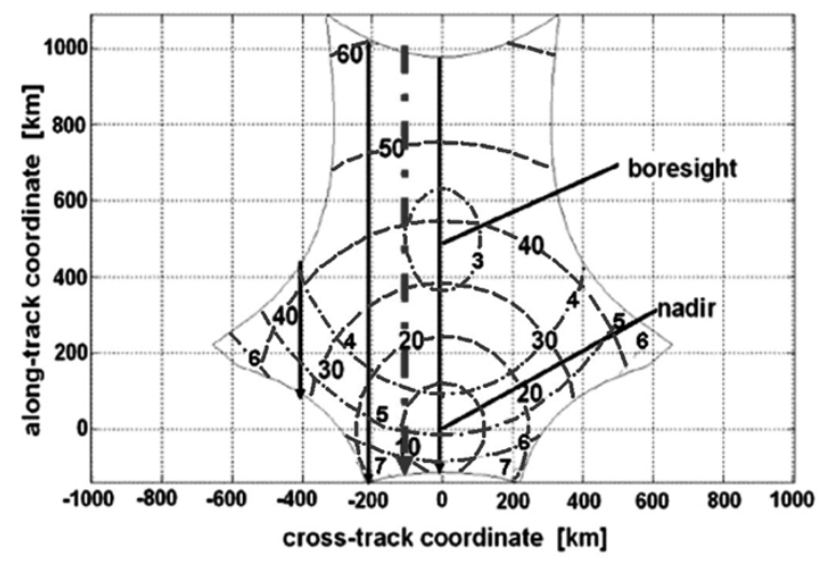

Fig. 2. (a) SMOS observation geometry. The half space in front of the array is mapped into the unit circle in $(\xi, \eta)$ coordinates. The alias-free FOV that is imaged by the instrument is marked in light gray and is enlarged up to the earth "aliases" limit by taking into account the sky contribution. (b) Properties of the alias-free FOV mapped from direction cosines coordinates in (a) to cross-track and along-track coordinates: incidence angle range from $0^{\circ}$ to $\sim 60^{\circ}$ (dashed contours centered at nadir) and radiometric sensitivity ranges from 3-7 K (dashed-dotted lines centered at boresight). Platform parameters: mean platform altitude of $775.5 \mathrm{~km}$, tilt angle of $32^{\circ}$ of the array boresight with respect to nadir. Instrument parameters are listed in Fig. 1(a). As the platform moves, a pixel on the earth is imaged in different positions of the alias-free FOV following a vertical line (vertical arrows).

TABLE II

Sketch of SMOS Processor LeVels and Data Products. See also http://www.esa.int/export/esaLP/ASE5HBUG0SC_smos_0.htm

\begin{tabular}{|c|c|}
\hline Raw data & ata in their original packets, as received from $\mathrm{t}$ \\
\hline Level 0 & $\begin{array}{l}\text { Observation data (cross-correlations between collected, NIR), satellite housekeeping data, } \\
\text { instrumentppayload housekeeping data. }\end{array}$ \\
\hline Level 1a & $\begin{array}{l}\text { Calibrated visibilities (cross-correlations), consolidated in pole-to-pole time-based segments, (location of the } \\
\text { spacecraft rather than location of the observation data). }\end{array}$ \\
\hline Level $1 \mathrm{~b}$ & $\begin{array}{l}\text { Snap-shot maps of radiometrically corrected and calibrated brightness temperature in the antenna reference } \\
\text { frame }\left(T_{x x}, T_{y y} \text { and in the full-polarimetric mode } T_{x y} \text { as well), obtained from the image reconstruction }\right. \\
\text { algorithm. Two products are generated at this level with different visibility function windows over land and } \\
\text { over sea. }\end{array}$ \\
\hline Level 1c & $\begin{array}{l}\text { Swath-based geo-referenced maps of brightness temperature in the pixel reference frame }\left(T_{h n} \text { and } T_{w} \text {, and }\right. \\
\left.\text { I }=T_{x x}+T_{y y}=T_{h n}+T_{w}\right) \text { for a number of incidence angles, with auxiliary information: geographical coordinates and } \\
\text { altitude, geometrical pixel properties, sun illumination etc. } \\
\text { Faraday rotation is corrected at this level. }\end{array}$ \\
\hline Level 2 & $\begin{array}{l}\text { Retrieval of SM over land and OS over sea at the same resolution and location as Level } 1 \text { source data. } \\
\text { Apply land-sea mask to locate mixed pixels. Apply appropriate corrections for SM retrieval. }\end{array}$ \\
\hline Level 3 & Spatial and temporal aggregation of Level 2 data. \\
\hline
\end{tabular}

$\beta$-mode, and $0.4 \mathrm{~s}$ in the $\gamma$-mode so as to achieve in these last three steps all the possible combinations between $y$ and $x$ polarizations, and obtain $T_{\mathrm{yy}}(\xi, \eta)$, as well as $T_{\mathrm{yx}}=1 / 2\left(T_{3}(\xi, \eta)+\mathrm{j} T_{4}(\xi, \eta)\right)$, where $T_{3}(\xi, \eta)$ and 
$T_{4}(\xi, \eta)$ are the third and fourth Stokes parameters. ${ }^{2}$ During the even periods ( $2.4 \mathrm{~s}$ long) the $x$ and $y$ polarizations are interchanged.

Due to the different integration time, in the odd periods the radiometric sensitivity of the $T_{\mathrm{xx}}(\xi, \eta)$ images is $\sqrt{3}$ times smaller than that of $T_{\mathrm{yy}}(\xi, \eta)$ and $T_{\mathrm{yx}}(\xi, \eta)$ (integration time is three times longer for $\left.T_{\mathrm{xx}}\right)$. For the same reason, in the even periods, the radiometric sensitivity of $T_{\mathrm{yy}}$ is $\sqrt{3}$ times smaller than that of $T_{\mathrm{xx}}(\xi, \eta)$ and $T_{\mathrm{yx}}(\xi, \eta)$. In addition, $T_{\mathrm{yx}}(\xi, \eta)$ and $T_{\mathrm{xy}}(\xi, \eta)$ are hermitian and can be averaged. Therefore, over homogeneous scenes and in the antenna reference frame "the sensitivity of the vertical, horizontal, and complex cross-brightness temperatures in the MIRAS polarimetric mode is thus the same" [4].

- Dual-polarization mode: $T_{\mathrm{pp}}(\xi, \eta)$ is sequentially measured at $p=x$ and $y$ linear polarizations in the antenna reference frame [Fig. 1(a)], with an integration time of $1.2 \mathrm{~s}$ at each polarization. A whole set of $T_{\mathrm{xx}}(\xi, \eta)$ and $T_{\mathrm{yy}}(\xi, \eta)$ images is then measured after $2.4 \mathrm{~s}$.

In the full-polarimetric mode, the effective integration time per polarization is smaller $(2.4 \mathrm{~s} / 3=0.8 \mathrm{~s})$ than in the dualpolarization mode, leading to a poorer radiometric sensitivity (larger noise) by a factor of $\sqrt{3 / 2}=1.22$ [4].

If the correlation of the noise in the visibility samples were taken into account, the larger the brightness temperature, the larger the noise [5]. However, this is a second-order effect, and the correlation in the noise in the visibility samples measured in the same time interval can be safely neglected. In this case, the resulting noise map in the $(\xi, \eta)$ domain is shown in Fig. 2(b) (contour lines from $\Delta T=3 \mathrm{~K}$ to $\Delta T=7 \mathrm{~K}$ ). In the boresight direction $[(\xi, \eta)=(0,0)]$, the radiometric sensitivity is $2.4 \mathrm{~K}$ (dual-polarization mode), and out-of-boresight it is amplified by the inverse of the antenna radiation pattern $t(\theta, \phi)$, and by the obliquity factor $\cos \theta=\sqrt{1-\xi^{2}-\eta^{2}}$ (Appendix II).

The retrieval of geophysical parameters can be formulated in the antenna $\left(T_{\mathrm{xx}}\right.$ and $\left.T_{\mathrm{yy}}\right)$ or in the earth reference frames $\left(T_{\mathrm{hh}}\right.$ and $T_{\mathrm{vv}}$ ), provided the appropriate corrections are applied. ${ }^{3}$ Both formulations require a precise knowledge of the observation geometry $(\psi)$ and the Faraday rotation $\left(\psi_{\text {Faraday }}\right)$, which is not negligible at L-band, and even worse, can exhibit strong inhomogeneities $(\sim 1 \mathrm{~km})$ within a SMOS pixel $(\geq 30 \mathrm{~km})$, which is an added difficulty in the correction. An alternative approach first proposed in [7] consists of formulating the retrieval problem in terms of the first Stokes parameter ${ }^{4}$ obtained as the sum of two brightness temperatures

$$
I=T_{\mathrm{xx}}+T_{\mathrm{yy}} \equiv T_{\mathrm{hh}}+T_{\mathrm{vv}}
$$

\footnotetext{
${ }^{2} T_{4}$ is negligible at L-band (it has never been measured within the resolution of any L-band radiometer), and therefore the images formed from the crosspolarization cross-correlations $T_{\mathrm{xy}}=\left(T_{3}-j T_{4}\right) / 2$ and $T_{\mathrm{yx}}=\left(T_{3}+j T_{4}\right) / 2$ are very likely to be the same: $T_{\mathrm{xy}}=T_{\mathrm{xy}} \approx T_{3} / 2$.

${ }^{3}$ Atmospheric/ionospheric losses and upwelling/downwelling brightness temperatures (mainly a function of surface height, atmospheric pressure, water content, and total electron content), and sky (cosmic/galactic) downwelling brightness temperature attenuated by the atmosphere/ionosphere in the downwelling path, scattered in the direction of observation and attenuated again by the atmosphere/ionosphere in the upwelling path, must be known and corrected for previously to retrieval of the geophysical parameters.

${ }^{4}$ Simulation studies and experimental data at L-band show that $T_{\mathrm{vh}} \approx 0$, both over the ocean and over land. In this case, $I \approx T_{\mathrm{hh}}+T_{\mathrm{vv}}=T_{\mathrm{xx}}+T_{\mathrm{yy}}$, which is computed in the antenna reference frame to avoid the singularities that appear in the earth reference frame, if the dual-polarization mode is used (Appendix I).
}

which is invazriant to rotations (does not require a knowledge of the geometric and Faraday rotations), and the radiometric sensitivity is not degraded [there are not singularities: see Appendix II and Fig. 8(c)]. This formulation of the problem can be used in the dual-polarization mode in order to maximize the integration time and achieve the best radiometric sensitivity. Therefore, it is not clear a priori which are the optimum operation modes and retrieval schemes.

The process to retrieve the geophysical parameters on a pixel basis is sketched below as follows.

- Determine if a pixel is a land, sea, or mixed pixel.

- Track the pixel as it moves in the alias-free FOV in a series of consecutive snap-shots. Tracking can be performed in the $(\xi, \eta)$ direction cosines coordinates [Fig. 2(a)] or in the along-track/cross-track coordinates [Fig. 2(b)]. The second option is preferred once the pixels are mapped on an earth-fixed grid.

- For each snap-shot, interpolate $T_{\mathrm{xx}}$ and $T_{\mathrm{yy}}$ (or $T_{\mathrm{hh}}$ and $T_{\mathrm{vv}}$ wherever there are not singularities) from the $(\xi, \eta)$ grid where the image reconstruction is performed ${ }^{5}$ to the geographical position of the pixel being tracked at that particular snap-shot. This process can be performed with the same window for all pixels, providing the same angular resolution in all directions, but different spatial resolution on ground, or with a "strip adaptive" processing window [8] tailored to provide the same spatial resolution at all directions.

- Correct for sky (cosmic and galactic noise) and atmospheric/ionospheric effects: signal attenuation, upwelling brightness temperature, downwelling brightness temperature scattered in the direction of observation.

- For each snap-shot, the error $\varepsilon$ (variance) between the model and the measured data at all incidence angles $\theta_{n}$ must be minimized, obtaining a set of estimated parameters $(\hat{\vec{x}})[9]$. Two different formulations are studied

$$
\begin{aligned}
\varepsilon= & \frac{1}{N_{\text {observations }}} \sum_{n}\left\{\left[\left(\bar{F}^{\text {model }}\left(\theta_{n}, \hat{\vec{x}}\right)\right.\right.\right. \\
& \left.-\bar{F}^{\text {data }}\left(\theta_{n}, \vec{x}\right)\right)^{T} \\
& \times\left(\overline{\bar{C}}_{\text {Full-pol/Dual }- \text { pol }}^{\text {earth }, \text { odd }(n) / \text { even }(n)}\right)^{-1} \\
& \left.\left.\times\left(\bar{F}^{\text {model }}\left(\theta_{n}, \hat{\vec{x}}\right)-\bar{F}^{\text {data }}\left(\theta_{n}, \vec{x}\right)\right)\right]\right\}
\end{aligned}
$$

where $N_{\text {observations }}$ is the number of measurements acquired of the same location in a satellite overpass, $\overline{\bar{C}}_{\text {Full-pol/Dual-pol }}$ is the error covariance matrix that depends on the SMOS operation mode and the reference frame (antenna or earth-based; see Appendixes I and II), and $\bar{F}^{\text {model/data }}\left(\theta_{n}, \hat{\vec{x}}\right)$ is a vector that contains the modeled and measured observables, and its structure depends on the formulation of the retrieval problem:

${ }^{5}$ To minimize error amplification effects, image reconstruction algorithms must operate on a $(\xi, \eta)$ grid that is the reciprocal of the $(u, v)$ one sampled by the array [1]. 
- $\bar{F}^{\text {model } / \text { data }}\left(\theta_{n}, \hat{\vec{x}}\right)=\left[T_{\mathrm{hh}}\left(\theta_{n}, \hat{\vec{x}}\right), T_{\mathrm{vv}}\left(\theta_{n}, \hat{\vec{x}}\right)\right]^{T}$ if the problem is formulated in terms of the brightness temperatures in the earth's reference frame.

- $\bar{F}^{\text {model } / \text { data }}\left(\theta_{n}, \hat{\vec{x}}\right)=\left[T_{\mathrm{xx}}\left(\theta_{n}, \hat{\vec{x}}\right), T_{\mathrm{yy}}\left(\theta_{n}, \hat{\vec{x}}\right)\right]^{T}$ if the problem is formulated in terms of the brightness temper-

- $\bar{F}^{\text {atures in the antennata }}\left(\theta_{n}, \hat{\vec{x}}\right)=\left[I\left(\theta_{n}, \hat{\vec{x}}\right)\right]^{T}=\left[T_{\mathrm{xx}}\left(\theta_{n}, \hat{\vec{x}}\right)+\right.$ $\left.T_{\mathrm{yy}}\left(\theta_{n}, \hat{\vec{x}}\right)\right]^{T}$ if the problem is formulated in terms of the first Stokes parameter.

The number of measurements of each pixel depends on the pixel's distance to the satellite ground-track. As the pixel's distance to the ground-track increases, the pixel is imaged fewer times, the angular variation is reduced [Fig. 2(b)], and the instrument's noise increases, which translates in a degraded performance in terms of the quality of the retrieved parameters. Figs. 3 and 4 show two examples of simulated brightness temperatures over sea and land plotted as a function of the incidence angle, as they would be measured by SMOS (in the full-polarimetric mode) for different conditions. The number of observations varies with the distance to the ground-track, and it is indicated in the title of each subplot. At the ground-track it is 73 , increasing up to $\sim 80$ at $\sim 220$ $\mathrm{km}$ from the ground-track and then rapidly decreases down to 11 at $\sim 550 \mathrm{~km}$.

The formulation of the retrieval algorithm (1) in terms of $\left(T_{\mathrm{hh}}, T_{\mathrm{vv}}\right)$ in the earth reference frame, or in terms of $\left(T_{\mathrm{xx}}, T_{\mathrm{yy}}\right)$ in the antenna reference frame, requires a precise knowledge of the Faraday rotation. The first formulation is advantageous in the full-polarimetric mode, since in the dual-polarization mode there are large errors in the regions close to the singularities [cross-like region in Fig. 8(c)]. As already mentioned, the singularity problem can be avoided if the retrieval is formulated in the antenna reference frame by replacing $T_{\mathrm{hh}}$ and $T_{\mathrm{vv}}$ by $T_{\mathrm{xx}}$ and $T_{\mathrm{yy}}$, respectively. However, since polarization mixing [(A1.1) and (A1.2)] reduces the angular signature of $T_{\mathrm{xx}}$ and $T_{\mathrm{yy}}$, while still requires a precise knowledge of the Faraday rotation to pass from $T_{\mathrm{hh}, \mathrm{vv}}^{\text {model }}$ to $T_{\mathrm{xx}, \mathrm{yy}}^{\mathrm{model}}$, this approach is not considered in this study.

Finally, the formulation of the problem in terms of $I$ avoids the singularity problem, and the need to know both Faraday and geometric rotations provides the smaller noise (in the dual-polarization mode), but since the angular variation of $I$ is smaller than that of $T_{\mathrm{hh}}$ and $T_{\mathrm{vv}}$, the number of parameters that can be retrieved may be affected as well.

In order to test different SMOS operation modes and retrieval approaches, numerical simulations for both sea surface salinity (SSS) and SM are based under the following assumptions and simplifications.

- The interferometric radiometer instrument is ideal, only perturbed by noise due to finite integration time. If the first Stokes parameter measured in the dual-polarization mode is used in the retrieval, the noise is computed for each pixel using the sum of the diagonal elements in (A2.2). If $T_{\mathrm{hh}}$ and $T_{\mathrm{vv}}$ are measured in the full-polarimetric mode, the noise is computed for each pixel as the elements $(1,1)$ and $(2,2)$ of $(\mathrm{A} 2.3 \mathrm{a})$ and $(\mathrm{A} 2.3 \mathrm{~b})$, depending if the snap-shot is odd or even.
- Regardless of its size and orientation, the pixel is homogeneous (land or sea), described by parameters that are constant in all its area: sea surface salinity, sea surface temperature, and wind speed in the case of sea; surface temperature, albedo, optical thickness, soil roughness, and moisture content, in the case of land.

- The brightness temperature model is the same in the direct model used to compute the simulated brightness temperatures and in the inverse model used in the retrieval. In the case of salinity retrievals, the impact of instrument biases and/or geophysical modeling errors has already been analyzed separately in [9].

These assumptions allow to make an homogeneous intercomparison study providing the minimum parameter retrieval errors. In any other situation (inhomogeneous pixel, or other instrumental errors rather noise), the retrieval performance will be degraded.

\section{A. Sea Surface Salinity Retrievals}

Sea surface salinity has already been retrieved from L-band radiometric measurements at constant incidence angles [10], and with multiangular measurements using WISE data [11], [12]. The main difficulty of the SSS retrieval problem is the sea state correction, usually characterized only in terms of the 10-m-height wind speed (WS) or the significant wave height (SWH). At nadir, the sensitivity of the brightness temperatures to $\mathrm{SSS}$ is $\Delta T_{\mathrm{hh}, \mathrm{vv}}\left(\theta=0^{\circ}\right) / \Delta \mathrm{SSS} \approx 0.5 \mathrm{~K} / \mathrm{psu}$ at an SST of $25{ }^{\circ} \mathrm{C}$, decreasing with temperature, and that to WS is $\Delta T_{\mathrm{hh}, \mathrm{vv}}\left(\theta=0^{\circ}\right) / \Delta \mathrm{WS} \approx 0.2 \mathrm{~K} /(\mathrm{m} / \mathrm{s})$. Taking into account the range of variability of the SSS (30-38 psu) and the WS (0 to $\sim 25 \mathrm{~m} / \mathrm{s}$ ), the WS may mask completely the SSS signature, unless it is properly accounted for. Since the wind produces a small variation of the brightness temperatures at both polarizations $\left(T_{\mathrm{hh}, \mathrm{vv}}\right)$, a first-order approximation has been used to model its effects [7], [9], [13]

$$
\begin{aligned}
T_{\mathrm{hh}, \mathrm{vv}}(\theta, \mathrm{SST}, \mathrm{SSS}, \mathrm{WS}) \approx e_{\mathrm{hh}, \mathrm{vv}}^{\text {Fresnel }}(\theta, \mathrm{SST}, \mathrm{SSS}) \\
\cdot \mathrm{SST}+\frac{\Delta T_{\mathrm{hh}, \mathrm{vv}}(\theta)}{\Delta \mathrm{WS}} \cdot \mathrm{WS}
\end{aligned}
$$

where $e_{\mathrm{hh}, \mathrm{vv}}^{\text {Fresnel }}=1-\Gamma_{\mathrm{hh}, \mathrm{vv}}\left(\theta, \varepsilon_{r}(\mathrm{SST}, \mathrm{SSS})\right)$ is the emissivity of a perfectly flat sea surface (no wind), and $\Gamma_{\mathrm{hh}, \mathrm{vv}}$ is the reflection coefficient ${ }^{6}$ that depends on the sea water dielectric constant that depends on the SST and SSS. The wind speed sensitivity has been modeled using a linear fit to Hollinger's measurements $\Delta T_{\mathrm{hh}, \mathrm{vv}}(\theta) / \Delta \mathrm{WS}=0.2\left(1 \pm \theta / 55^{\circ}\right)[\mathrm{K} /(\mathrm{m} / \mathrm{s})][14]$.

Additional advantages of the formulation of the retrieval problem in terms of the first Stokes parameter are the following.

- It minimizes the effect of the uncertainty in the dielectric permittivity models [15], [16], since the difference of the first Stokes parameter $I=T_{\mathrm{hh}}+T_{\mathrm{vv}}$ computed with the two models is approximately constant versus incidence angle [13].

\footnotetext{
${ }^{6}$ The reflection coefficient is the square of the absolute value of the Fresnel reflection coefficient of the electric field.
} 
a1)
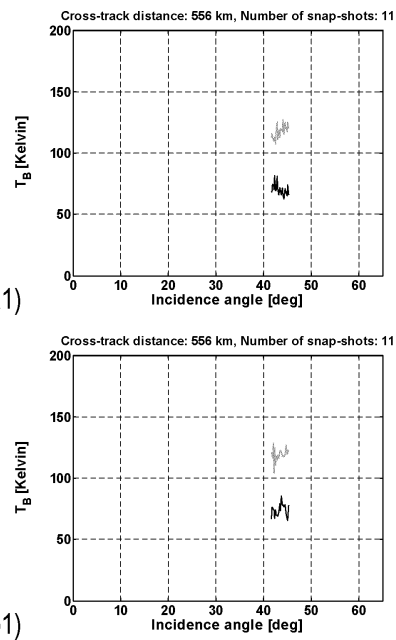

a2)
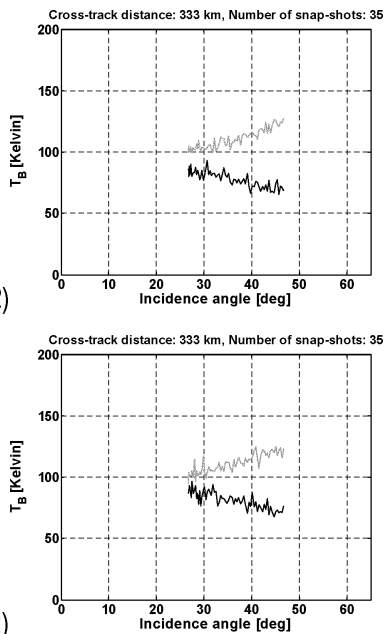

a3)

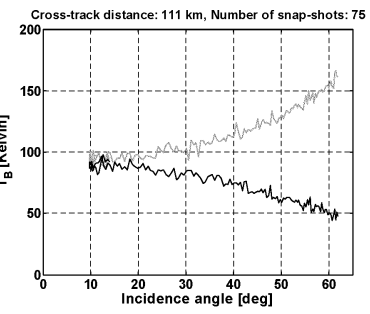

b3)

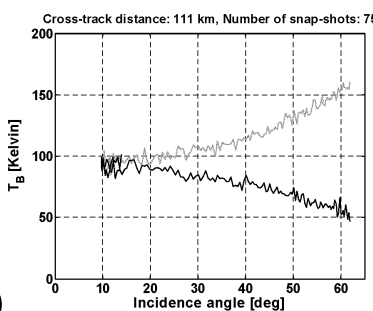

a4)

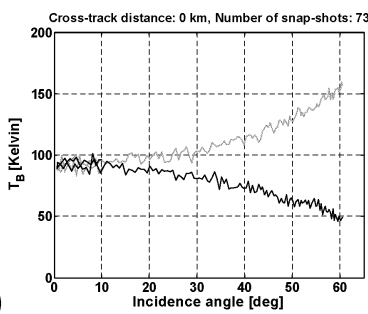

b4)

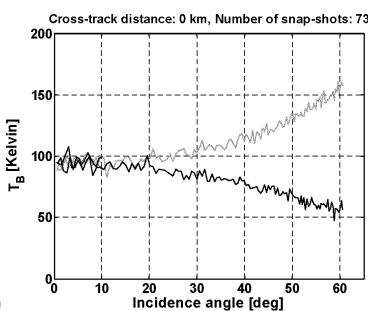

Fig. 3. Simulated series of brightness temperature values as a function of the pixel cross-track position [Fig. $2(\mathrm{~b})]$ over the ocean for $(\mathrm{a}) \mathrm{SSS}=35$ psu, SST $=$ $15^{\circ} \mathrm{C}, U_{10}=0 \mathrm{~m} / \mathrm{s}$ and (b) SSS $=35 \mathrm{psu}$, SST $=15{ }^{\circ} \mathrm{C}, U_{10}=10 \mathrm{~m} / \mathrm{s}$. Vertical polarization: upper curves, and horizontal polarization: lower values. The number of observations for each cross-track distance is indicated in the titles of each subplot.

a1)
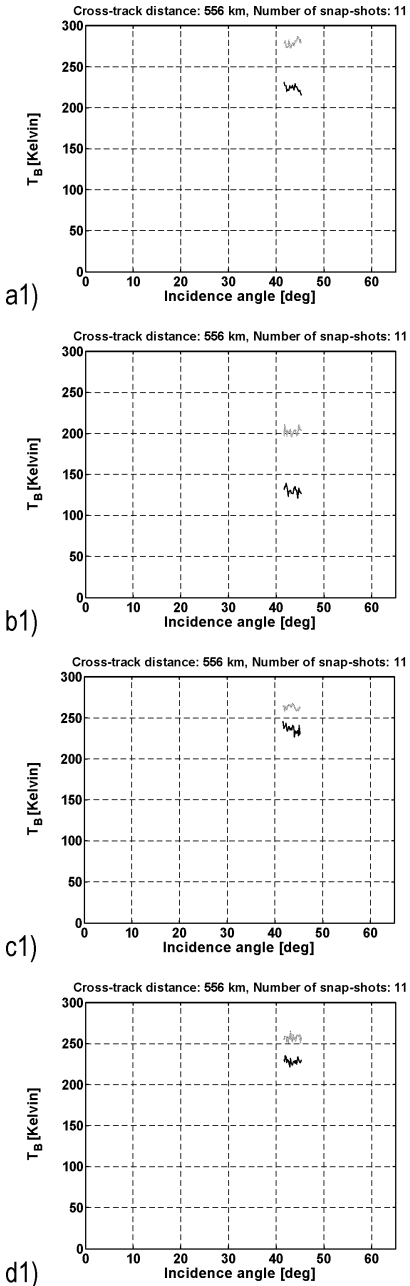

a2)

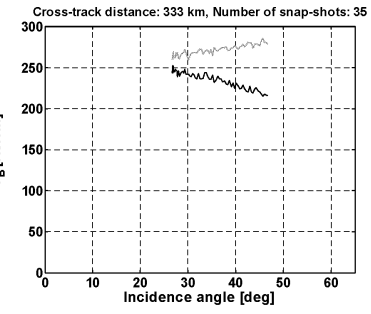

b2)

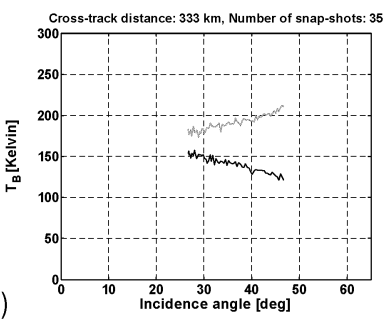

c2)

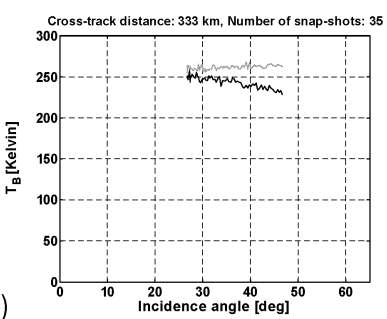

c3)

b3)

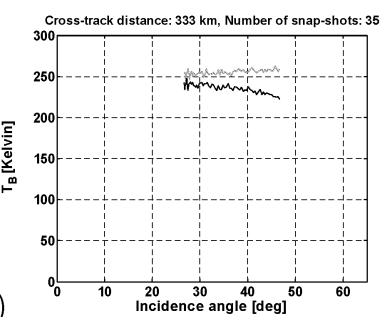

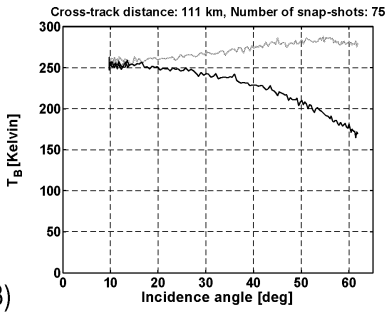
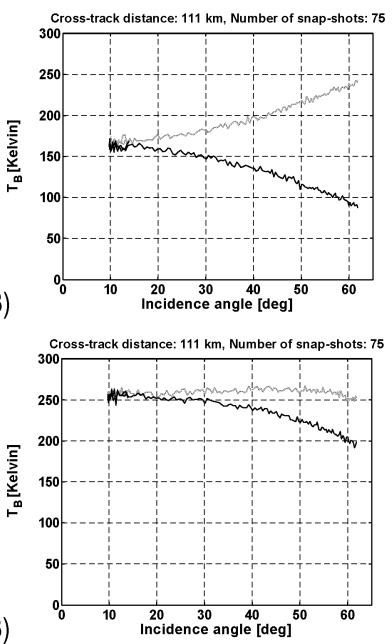

a4)

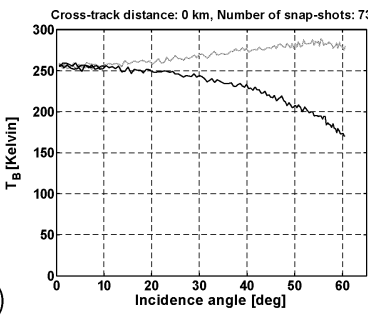

b4)

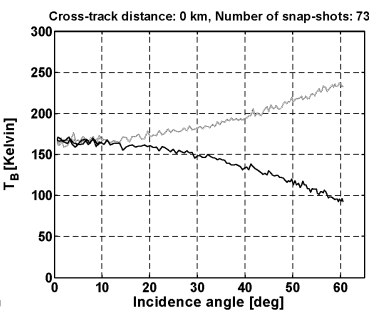

c4)
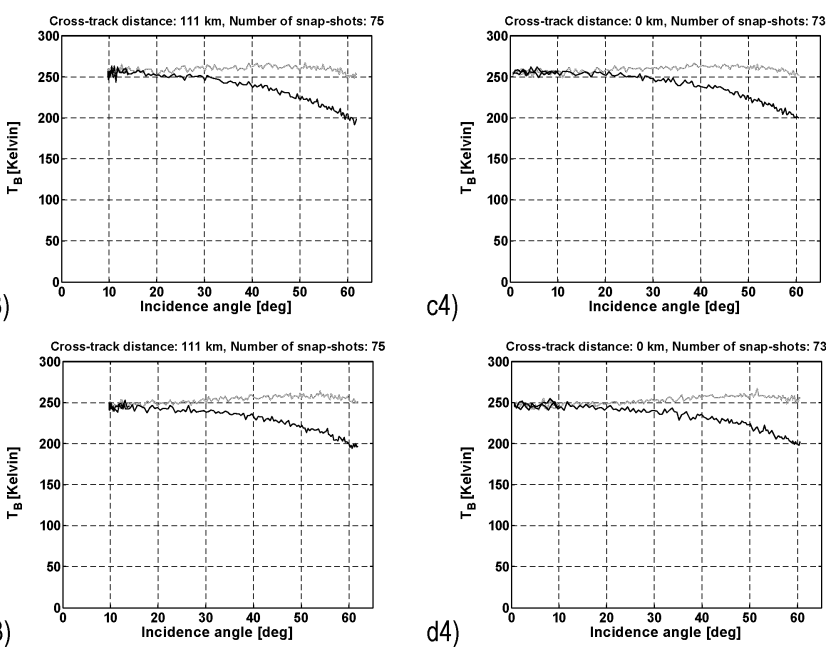

Fig. 4. Simulated series of brightness temperature values at vertical (upper curves) and horizontal (lower curves) polarizations as a function of the pixel cross-track position [Fig. 2(b)] for $T_{\text {soil }}=290 \mathrm{~K}$ and (a) no vegetation and flat, dry soil SM $=0$, (b) no vegetation and flat, wet soil SM $=0.4$, (c) vegetation-covered $(\tau=1 \mathrm{Nep}, \omega=0.1)$, and roughed $\left(h_{\mathrm{s}}=1\right)$, dry soil $\mathrm{SM}=0$, and (d) vegetation-covered $(\tau=1 \mathrm{Nep}, \omega=0.1)$, and roughed $\left(h_{\mathrm{s}}=1\right)$, wet soil SM $=0.4$. The number of observations for each cross-track distance is indicated in the titles of each subplot. 

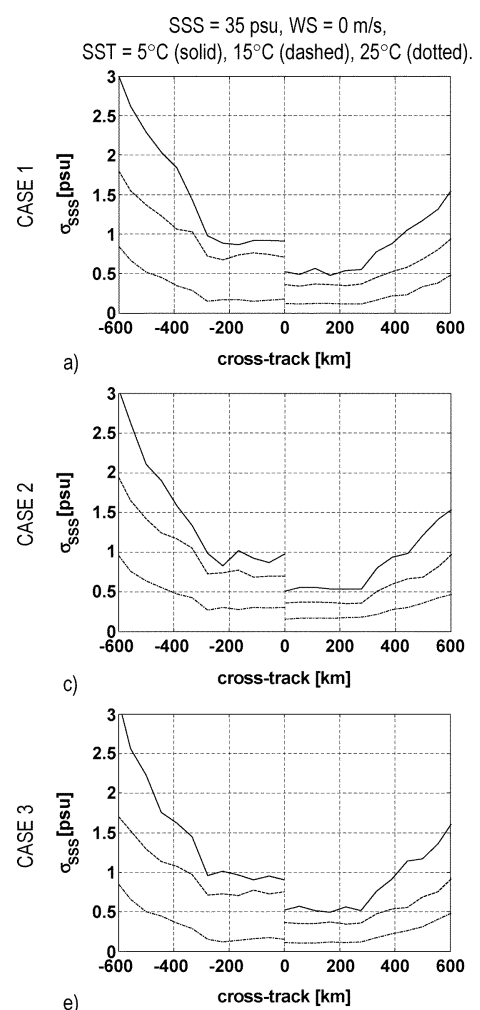

e)

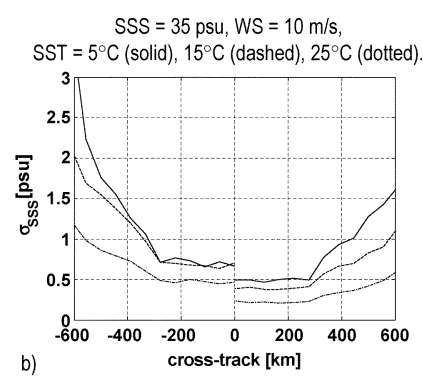

b)

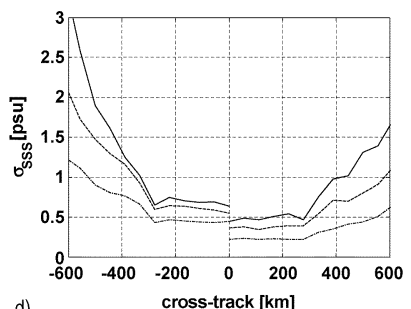

d)

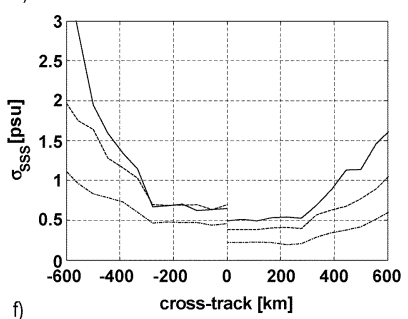

f)
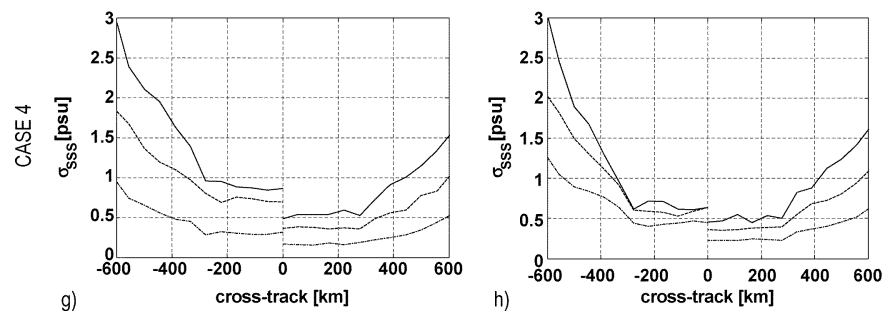

Fig. 5. Sea surface salinity retrieval algorithm performance versus pixel position in the swath. Left column: wind speed $=0 \mathrm{~m} / \mathrm{s}$, right column: wind speed $=10 \mathrm{~m} / \mathrm{s}$. In each plot: first Stokes parameter computed in dualpolarization mode (left side) and $T_{\mathrm{hh}}$ and $T_{\mathrm{vv}}$ computed in full-polarimetric mode with perfect Faraday and geometric rotation (right side). From top to bottom: Case 1: all parameters as free variables, Case 2: WS auxiliary information, Case 3: SST auxiliary information, and Case 4: WS and SST auxiliary information.

- It minimizes the effect of swell, since $I=T_{\mathrm{hh}}+T_{\mathrm{vv}}$ under swell conditions is approximately constant versus incidence angle [17].

The minimization problem uses the Levenberg-Marquardt method with a cubic polynomial line search and Gill-Murray Hessian update methods ${ }^{7}$ [18].

The following four different retrieval methods have been analyzed.

- Case 1: SSS, SST, and WS are free variables [Fig. 5(a) and (b)].

- Case 2: SSS and SST are free variables, and WS is perfectly known from auxiliary data [Fig. 5(c) and (d)].

- Case 3: SSS and WS are free variables, and SST is perfectly known from auxiliary data [Fig. 5(e) and (f)].

- Case 4: SSS is a free variable, and SST and WS are perfectly known from auxiliary data [Fig. 5(g) and (h)].

\footnotetext{
${ }^{7}$ Matlab optimization toolbox.
}

"Free variables" are assigned to an initial value equal to the measured one by a different sensor or model [11]-[13] (including a random term to simulate the measurement error), and they are left to vary inside an interval of width equal to plus and minus the standard deviation of the error associated to the sensors providing that measurement. In these simulations, random initial values are selected: $\mathrm{SSS}=\mathrm{SSS}_{0} \pm 2 \mathrm{psu}$, $\mathrm{SSTT}=\mathrm{SST}_{0} \pm 1{ }^{\circ} \mathrm{C}$, and $\hat{\mathrm{WS}}=\mathrm{WS}_{0} \pm 2.5 \mathrm{~m} / \mathrm{s}$ (Gaussian pdf parameters: mean value \pm 1 standard deviation).

For the four cases, Fig. 5(a)-(h) presents the rms error computed from the retrieved SSS and the true SSS from 200 Monte Carlo simulations. On the left column [plots Fig. 5(a), (c), (e), and $(\mathrm{g})]$ the conditions are $\mathrm{SSS}_{0}=35 \mathrm{psu}, \mathrm{SST}_{0}=5{ }^{\circ} \mathrm{C}$ (solid line), $15{ }^{\circ} \mathrm{C}$ (dashed line), $25{ }^{\circ} \mathrm{C}$ (dotted line), and $\mathrm{WS}_{0}=$ $0 \mathrm{~m} / \mathrm{s}$. On the right column [plots Fig. 5(b), (d), (f), and (h)], the conditions are the same except that $\mathrm{WS}_{0}=10 \mathrm{~m} / \mathrm{s}$. On the left-hand side of each plot, simulation results correspond to the use of the first Stokes parameter measured in the dual-polarization mode, and on the right-hand side, to the use of $T_{\mathrm{hh}}$ and $T_{\mathrm{vv}}$ measured in the full-polarimetric mode assuming perfect Faraday and geometric rotation corrections. The analysis of Fig. 5(a)-(h) shows the following.

- The SSS retrieval error decreases with increasing SST, since the brightness sensitivity to SSS increases with SST.

- The SSS retrieval error in terms of $I$ computed in the dual-polarization mode is higher than in terms of $T_{\mathrm{hh}}$ and $T_{\mathrm{vv}}$ computed in the full-polarimetric mode because the number of measurements is halved, ${ }^{8}$ and it is not compensated by the smaller noise. ${ }^{9}$ For WS $=0 \mathrm{~m} / \mathrm{s}$, the degradation factor is $\sim 2$ for cold water and decreases with increasing SST. For WS $=10 \mathrm{~m} / \mathrm{s}$, the degradation factor is nearly constant versus SST.

- The SSS retrieval error is very similar in the full-polarimetric mode for both $\mathrm{WS}_{0}=0 \mathrm{~m} / \mathrm{s}$ and $10 \mathrm{~m} / \mathrm{s}$, and the estimated WS values are very close to the actual ones (see [13] for results with experimental data, results not shown in this study). In the dual-polarization case, using the first Stokes parameter the error even slightly decreases for $\mathrm{WS}_{0}=10 \mathrm{~m} / \mathrm{s}$, since the wind effect in $I$ is approximately a constant value versus incidence angle and absorbs errors in the estimation of SST.

- The SSS retrieval error is very similar in all four cases, which allows to have some errors in the auxiliary data. If the SST and/or WS were known from auxiliary data, but with a given error, and their corresponding values were set as constant parameters, the SSS retrieval error would be larger.

The trend of the retrieved values is in agreement with recent results from other authors in dual-polarization and

${ }^{8}$ The number of data points is halved since in each snap-shot, a pair of measurements $\left(T_{\mathrm{xx}}\right.$ and $\left.T_{\mathrm{yy}}\right)$ are added to generate a single $I$ value.

${ }^{9}$ Not to confuse: 1) the radiometric sensitivity that depends on the integration time per snap-shot (that depends on the operation mode) and the pixel's position in the alias-free FOV (due to the antenna pattern and the obliquity factor, Appendix II); and 2) the number of measurements or observations of a given pixel as it passes through the alias-free FOV, which depends on the distance to the ground-track. It is the combination of both things, plus the geophysical parameter retrieval algorithm and auxiliary data availability, that determines the ultimate retrieval performance. 
full-polarimetric modes, assuming that Faraday rotation effects are the same at a scale of $500 \mathrm{~km}$ and are perfectly corrected for [19]. If the ionosphere is not homogeneous within a SMOS pixel the retrieval performance will degrade, while with the first Stokes parameter the performance will be the same. Similar results are found for SSS $=30$ psu.

Finally, depending on the accuracy required and the temporal/spatial variability (Table I), the retrieved SSS must be averaged in time and/or space. In [9], the result of using SSS temporal averages in blocks of 10 and 30 days, to reach the goal of 0.1-psu salinity error is shown, despite the natural variability of the variable under measurement.

\section{B. Soil Moisture Retrievals}

Over land, the dynamic range of the brightness temperature is larger than over sea (Fig. 4, for different soil moisture conditions), and additionally, the SM required accuracy is not as critical as in the SSS retrieval problem. The brightness temperature model used in the simulations is the $\tau-\omega$ model, as used in the multiangular and dual-polarization soil moisture retrievals presented in [20] and [21] $]^{10}$

$$
\begin{aligned}
T_{\mathrm{pp}}=\left[\left(1+\frac{\Gamma_{\mathrm{bare}}^{\mathrm{p}}}{\mathrm{L}_{\mathrm{veg}}^{\mathrm{p}}}\right) \cdot\left(1-\frac{1}{\mathrm{~L}_{\mathrm{veg}}^{\mathrm{p}}}\right)\left(1-\omega_{\mathrm{p}}\right)\right. \\
\left.\quad+\left(\frac{1-\Gamma_{\mathrm{bare}}^{\mathrm{p}}}{\mathrm{L}_{\mathrm{veg}}^{\mathrm{p}}}\right)\right] \cdot T_{\text {soil }} \quad(\mathrm{p}=\text { h or } \mathrm{v})
\end{aligned}
$$

and

$$
\begin{aligned}
\Gamma_{\text {bare }}^{\mathrm{p}}\left(\theta, \varepsilon_{r}\right)= & {\left[(1-\mathrm{Q}) \cdot \Gamma_{\mathrm{spec}}^{\mathrm{p}}\left(\theta, \varepsilon_{r}\right)\right.} \\
& \left.+\mathrm{Q} \cdot \Gamma_{\mathrm{spec}}^{\mathrm{q}}\left(\theta, \varepsilon_{r}\right)\right] \exp \left(-\mathrm{h}_{\mathrm{s}}\right) \\
\mathrm{L}_{\mathrm{veg}}^{\mathrm{p}}= & \exp \left(\frac{\tau_{\mathrm{p}}}{\cos \theta}\right)
\end{aligned}
$$

where $\Gamma_{\text {bare }}^{\mathrm{p}}$ is the reflection coefficient of the (flat) soil that depends on the soil moisture through the dielectric constant, $\mathrm{h}_{\mathrm{s}}$ is a soil roughness parameter, $\mathrm{Q}$ is the polarization mixing factor, $\mathrm{L}_{\mathrm{veg}}^{\mathrm{p}}$ is the vegetation attenuation, $\tau_{\mathrm{p}}$ is the vegetation opacity, and $\omega_{\mathrm{p}}$ is the vegetation single-scattering albedo. For simplicity, it has been assumed that $\tau_{\mathrm{p}}$ and $\omega_{\mathrm{p}}$ are the same at both polarizations and independent of the incidence angle.

In the SM retrieval problem, the number of variables is larger than in the SSS retrieval problem: $\hat{\vec{x}}=$ soil surface moisture $(\mathrm{SM})$, soil surface temperature $\left(T_{\text {soil }}\right)$, roughness $\left(\mathrm{h}_{\mathrm{s}}\right)$, vegetation opacity $(\tau)$, and albedo $(\omega)$.

The minimization technique used is the same as for the SSS retrieval problem (Section II-A). The following three different retrieval methods have been analyzed.

- Case 1: SM, $T_{\text {soil }}, \mathrm{h}_{\mathrm{s}}, \tau$, and $\omega$ are free variables [Fig. 6(a) and (b)].

- Case 2: SM, $\tau$, and $\omega$ are free variables, and $T_{\text {soil }}$ and $h_{\mathrm{s}}$ are known without error from auxiliary data [Fig. 6(c) and (d)].

${ }^{10}$ In the present study, the single-scattering albedo has not been neglected $(\omega \neq 0)$.

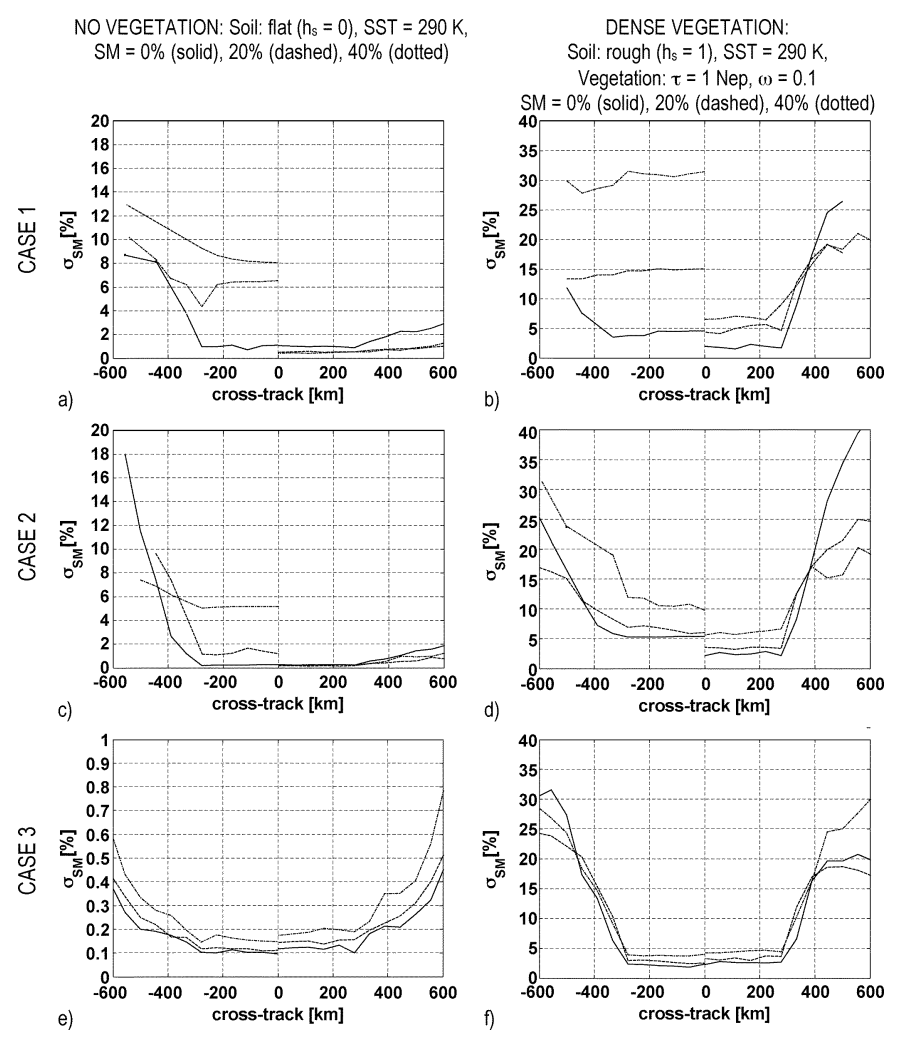

Fig. 6. Soil moisture retrieval algorithm performance versus pixel position in the swath. Left column: no vegetation, right column: dense vegetation. In each plot: first Stokes parameter computed in dual-polarization mode (left side) and $T_{\mathrm{hh}}$ and $T_{\mathrm{vv}}$ computed in full-polarimetric mode with perfect Faraday and geometric rotation (right side). From top to bottom: Case 1: all parameters as free variables, Case 2: soil $\left(T_{\text {soil }}\right.$ and $\left.\mathrm{h}_{\mathrm{s}}\right)$ auxiliary information, Case 3: soil $\left(T_{\text {soil }}\right.$ and $\mathrm{h}_{\mathrm{s}}$ ) and vegetation ( $\omega$ and $\tau$ ) auxiliary information.

- Case 3: SM is a free variable, and $T_{\text {soil }}, \mathrm{h}_{\mathrm{s}}, \tau$, and $\omega$ are known without error from auxiliary data [Fig. 6(e) and (f)].

Even though the sensitivity of the error (2) is larger than in the SSS case, the speed and accuracy of the retrieval is also improved by reducing the search limits of the free variables within reasonable bounds: $0 \leq \hat{\mathrm{SM}} \leq 0.4, \hat{T}_{\text {soil }}=T_{\text {soil } 0} \pm 2{ }^{\circ} \mathrm{C}$, $0 \leq \hat{h}_{\mathrm{s}} \leq 1,0 \leq \hat{\tau} \leq 1 \mathrm{Nep}$, and $0 \leq \hat{\omega} \leq 0.3$. Since the soil surface temperature is expected to geographically vary more over land than over the sea, and the temperature of the vegetation layer can be different from the soil, the range of values is larger than in the SSS retrieval problem.

Fig. 6(a)-(f) presents the rms error computed from the retrieved SM and the true SM from 200 Monte Carlo simulations. On the left column [plots Fig. 6(a), (c), and (e)], a very ideal scenario is presented: a perfectly flat soil without vegetation. The conditions are: $\mathrm{SM}_{0}=0 \%$ (solid line), $20 \%$ (dashed line), and $40 \%$ (dotted line), $T_{\text {soil } 0}=17^{\circ} \mathrm{C}, \mathrm{h}_{\mathrm{s} 0}=0, \tau_{0}=0$, and $\omega_{0}=0$ (no vegetation). On the right column [Fig. 6(b), (d), and (f)], a difficult scenario is presented: very rough soil covered by a dense vegetation layer. The conditions are: $\mathrm{SM}_{0}=0 \%$ (solid line), $20 \%$ (dashed line) and $40 \%$ (dotted line), $T_{\text {soil } 0}=17^{\circ} \mathrm{C}$, $\mathrm{h}_{\mathrm{s} 0}=1, \tau_{0}=1 \mathrm{Nep}$, and $\omega_{0}=0.1$. Sample brightness temperatures for these two scenarios are provided in Fig. 4. The most important feature is the strong decrease of the brightness temperatures sensitivities to SM in the presence of vegetation. On the left-hand side of each plot simulation results correspond to 
the use of the first Stokes parameter measured in the dual-polarization mode, and on the right-hand side to the use of $T_{\mathrm{hh}}$ and $T_{\mathrm{vv}}$ measured in the full-polarimetric mode assuming perfect Faraday and geometric rotation corrections.

Despite our simulation parameters are very stringent, our analysis [Fig. 6(a)-(f)] confirm previously reported results [20], and retrievals with experimental L-band radiometric data [21], that have formulated the retrieval process in terms of $T_{\mathrm{hh}}$ and $T_{\mathrm{vv}}$ over the earth's surface. From this analysis, the following conclusions can be summarized.

- In most retrieval schemes (use of different auxiliary data), the SM retrieval error is smaller over bare soils or sparse vegetation covers than over dense vegetation-covered soils [21], and it is smaller if the full-polarimetric mode is used ( $T_{\mathrm{hh}}$ and $T_{\mathrm{vv}}$ over the earth's surface ${ }^{11}$ ), instead of the dual-polarization one with the first Stokes parameter ${ }^{12}$ due to the larger angular variation of $T_{\mathrm{hh}}$ and $T_{\mathrm{vv}}$ as compared to that of I. This can be understood, since the number of measurements is halved.

- The SM retrieval error rapidly increases above $\sim 300 \mathrm{~km}$ half-swath in most conditions as the number of measured data rapidly decreases [Fig. 2(b)], in accordance with [21].

- The SM retrieval error decreases with drier soils, confirming the results presented previously in [21]. This is attributed to the smaller relative error in the brightness temperatures (same radiometric sensitivity, but larger brightness temperature).

- Over densely vegetated soils $(\tau=1 \mathrm{Nep})$, knowledge of soil parameters $\left(T_{\text {soil }}\right.$ and $\left.h_{\mathrm{s}}\right)$ improves the quality of the SM retrievals, but the SMOS requirements are not met $\left(\sigma_{\mathrm{SM}}=4 \%\right.$, Table I $)$.

- Knowledge of the vegetation parameters further improves the SM retrieval errors, especially if the first Stokes parameter is used in dual-polarization mode. In this case, within a $600-\mathrm{km}$ swath, the retrieved SM errors within requirements (Table I). Under the assumption that the timescale of variations of $\tau$ is substantially higher than for SM, a scheme has been suggested to use $\tau$ values retrieved in the central part of the field of view on a previous orbit, as a priori information in order to improve the retrieval conditions for SM in the outer parts of the field of view [21].

However, experimental measurements over vineyard fields have shown a rapid opacity increase after soil irrigation due to water absorption [22, Fig. 7]. In this situation, the preferred option is to retrieve all vegetation parameters in a $\sim 600-\mathrm{km}$ swath in one satellite overpass from the multiangular radiometric measurements themselves.

- Fig. 7 shows the retrieval capabilities for $\tau$ and $\omega$, for the dual-polarization (left side) and full-polarimetric (right side) modes and different soil moistures. The error estimates are very large if the first Stokes parameter is used, but dramatically improve in the full-polarimetric mode

\footnotetext{
${ }^{11} T_{\mathrm{vv}}$ and $T_{\mathrm{hh}}$ over the earth's surface can only be obtained in the so-called full-polarimetric mode, since in the dual-polarization mode the errors near the singularity regions [Fig. 8(a)] tend to infinite.

${ }^{12}$ In Fig. 6(e), the situation is the inverse one, which may be due to the numerical noise associated to the very low retrieved errors.
}
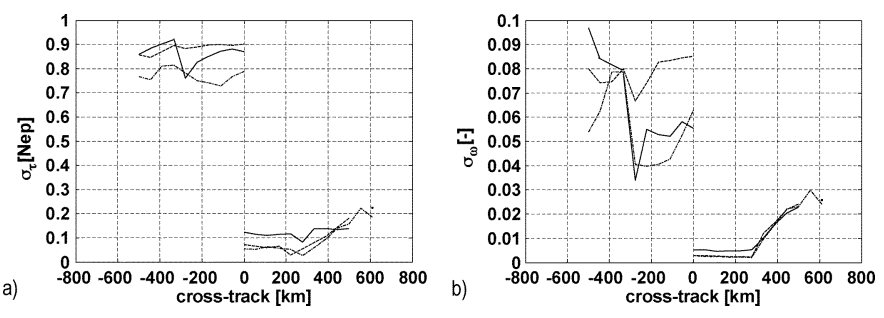

Fig. 7. Retrieved (a) vegetation opacity $(\tau)$ and (b) single-scattering albedo $(\omega)$ corresponding to Case 1 with thick vegetation layer [Fig. 6(b)], for dual-polarization mode using the first Stokes parameter (left side), or for the full-polarimetric mode using $T_{\mathrm{hh}}$ and $T_{\mathrm{vv}}$ over the earth's surface. Simulation parameters: vegetation: $\tau=1 \mathrm{Nep}, \omega=0.1$, soil: $T_{\text {soil }}=290 \mathrm{~K}, \mathrm{~h}_{\mathrm{s}}=1$, and SM $=0 \%$ (solid line), $20 \%$ (dashed line), and 40\% (dotted line).

( $\left.\tau=1 \mathrm{Nep}, \sigma_{\tau}=0.1 \mathrm{Nep}, \omega=0.1, \sigma_{\omega}=0.01\right)$. Contrary to the SM estimates, the errors in the retrieved parameters decrease for wet soils, in accordance to [21], since the brightness temperature contrast between bare and vegetated wet soils is larger than if the soils were dry (see Fig. 4).

- For rough, homogeneous, and dense vegetation-covered soils, the rms error is smaller than $\sigma_{\mathrm{SM}}=0.04 \mathrm{~m}^{3} / \mathrm{m}^{3}$ (4\%) only for a $\sim 600-\mathrm{km}$ swath, for dry and moderately wet soils provided auxiliary information is used.

\section{CONCLUSION}

This study has analyzed the impact of different operation modes of SMOS (dual-polarization and full-polarimetric), different SSS and SM retrieval methods, and different auxiliary data for an ideal instrument just limited by thermal noise due to finite integration time, and for an ideal scenario with constant geophysical parameters (homogeneous for all the varying pixels' size and orientation) and perfect correction of Faraday and geometric rotations. The main conclusions can be summarized below as follows.

- Sea surface salinity retrievals show a better performance if the full-polarimetric mode is used.

- Soil moisture retrievals perform much better if the full-polarimetric mode is used, which allows also to infer vegetation parameters (opacity and albedo) over a $\sim 600-\mathrm{km}$ swath, even over dense vegetation areas.

However, since the use of $I=T_{\mathrm{xx}}+T_{\mathrm{yy}}$ measured in the antenna reference frame and in the dual-polarization mode is more robust in the presence of geometric rotations and Faraday rotation (at any spatial scale, or even within the SMOS pixel), it should not be discarded, especially in the SSS retrieval case, which has the most stringent accuracy requirements.

The performance of the SSS retrieval algorithms is not significantly altered when the model parameters are initialized to the values of the auxiliary data, and are then left as free variables to be adjusted in the optimization process (Case 1), or when error-free auxiliary data are used for all model variables (Case 4). In the SM retrieval algorithms formulated in terms of the first Stokes parameter, the use of error-free auxiliary data does significantly improve the quality of the retrieved SM, although rarely satisfies the requirements $\left(\sigma_{\mathrm{SM}}=4 \%\right)$. In the full-polarimetric mode, the improvement is small. In both SSS 


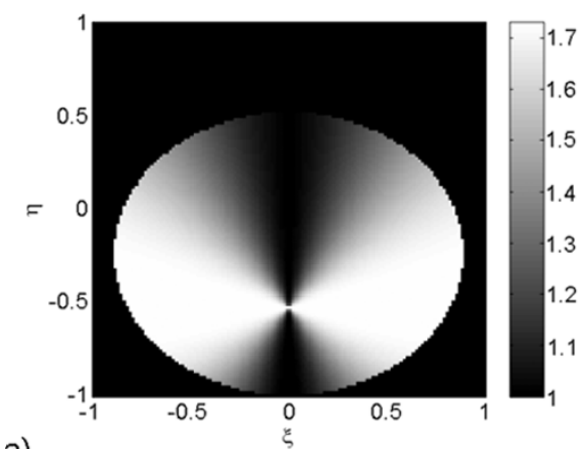

a)

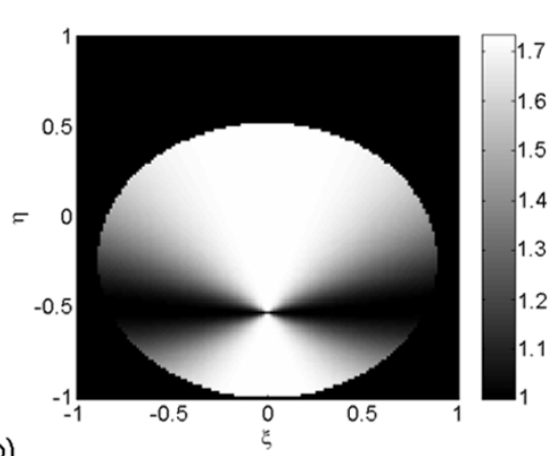

b)

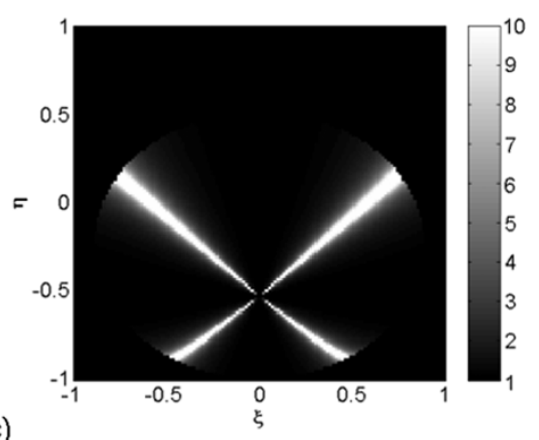

Fig. 8. Amplification of the noise standard deviation in the transformation from the antenna reference frame to the earth reference frame (one over $\sigma$ times the square root of the noise covariance matrix elements). (a) Full-polarimetric mode at H-polarization odd period or V-polarization even period [element 4-4 in (A2.3a) or 1-1 in (A2.3b)], (b) full-polarimetric mode at V-polarization odd period or H-polarization even period [element 4-4 in (A2.3a) or 1-1 in (A2.3b)], and (c) dual-polarization mode [element 1-1 or 2-2 in (A2.5)]. Cross-like region is singular. Graybar truncated at 10 for better representation.

and SM retrieval algorithms, the simultaneous retrieval of the following several variables eases the stringent requirements on the accuracy of the auxiliary data need:

- for sea salinity retrieval: sea surface temperature, wind speed and significant wave height;

- for soil moisture retrieval: soil moisture, soil surface temperature, soil roughness, vegetation opacity, and albedo.

These results can help to define the SMOS operation mode: dual-polarization mode over oceanic regions and sea surface salinity retrievals using the first Stokes parameter (computed in the antenna reference frame), and full-polarimetric mode over land regions. These results should also help to reduce the amount of data to be stored and down-linked, and can be taken into account in the definition of the SMOS L2 processor.

\section{APPENDIX I \\ TRANSFORMATION FROM THE ANTENNA TO THE EARTH REFERENCE FRAMES}

A significant difference between the two modes of operation of SMOS is the brightness temperatures transformation from the antenna to the earth reference frame.

- Full-polarimetric mode: the brightness temperatures in the earth reference frame ${ }^{13}\left(T_{\mathrm{hh}}, T_{\mathrm{vv}}, T_{\mathrm{hv}}\right.$, and $\left.T_{\mathrm{vh}}\right)$ are computed from the measured brightness temperatures in the antenna reference frame $\left(T_{\mathrm{xx}}, T_{\mathrm{yy}}, T_{\mathrm{xy}}\right.$, and $\left.T_{\mathrm{yx}}\right)$ by inverting [6, eq. 3]

$$
\begin{array}{r}
{\left[\begin{array}{c}
T_{\mathrm{xx}} \\
T_{\mathrm{xy}} \\
T_{\mathrm{yx}} \\
T_{\mathrm{yy}}
\end{array}\right]=\left[\begin{array}{cccc}
\mathrm{A}^{2} & \mathrm{AB} & \mathrm{AB} & \mathrm{B}^{2} \\
-\mathrm{AB} & \mathrm{A}^{2} & -\mathrm{B}^{2} & \mathrm{AB} \\
-\mathrm{AB} & -\mathrm{B}^{2} & \mathrm{~A}^{2} & \mathrm{AB} \\
\mathrm{B}^{2} & -\mathrm{AB} & -\mathrm{AB} & \mathrm{A}^{2}
\end{array}\right]\left[\begin{array}{c}
T_{\mathrm{hh}} \\
T_{\mathrm{hv}} \\
T_{\mathrm{vh}} \\
T_{\mathrm{vv}}
\end{array}\right]} \\
\Rightarrow \bar{T}_{\mathrm{B}, \text { antenna }}=\overline{\overline{\mathrm{M}}}_{\text {Full-pol }} \bar{T}_{\mathrm{B}, \text { earth }}
\end{array}
$$

where $\mathrm{A}=\cos \left(\psi_{\text {Faraday }}-\psi\right)$ and $\mathrm{B}=\sin \left(\psi_{\text {Faraday }}-\psi\right)$, $\psi_{\text {Faraday }}$ is the rotation angle through the ionosphere due to Faraday effect, and $\psi$ is a geometrical-related rotation between polarizations.

\footnotetext{
${ }^{13} T_{\mathrm{hh}}$ and $T_{\mathrm{vv}}$ correspond to the horizontal and vertical brightness temperatures, usually referred as $T_{\mathrm{h}}$ and $T_{\mathrm{v}}$. In this study, the $T_{\mathrm{hh}}$ and $T_{\mathrm{vv}}$ nomenclature is followed to indicate that it has been obtained from interferometric measurements of two antennas at the same polarization.
}

- Dual-polarization mode: assuming $T_{\mathrm{hv}}=T_{\mathrm{vh}}=0$, the brightness temperatures in the earth reference frame $\left(T_{\mathrm{hh}}\right.$ and $T_{\mathrm{vv}}$ ) are computed from the measured brightness temperatures in the antenna reference frame $\left(T_{\mathrm{xx}}\right.$ and $\left.T_{\mathrm{yy}}\right)$ by inverting [6]

$$
\begin{aligned}
{\left[\begin{array}{l}
T_{\mathrm{xx}} \\
T_{\mathrm{yy}}
\end{array}\right]=\left[\begin{array}{ll}
\mathrm{A}^{2} & \mathrm{~B}^{2} \\
\mathrm{~B}^{2} & \mathrm{~A}^{2}
\end{array}\right]\left[\begin{array}{l}
T_{\mathrm{hh}} \\
T_{\mathrm{vv}}
\end{array}\right] } \\
\quad \Rightarrow \bar{T}_{\mathrm{B}, \text { antenna }}=\overline{\overline{\mathrm{M}}}_{\text {Dual-pol }} \bar{T}_{\mathrm{B}, \text { earth }}
\end{aligned}
$$

which is singular whenever $\mathrm{A}=\mathrm{B} \Rightarrow \psi_{\text {Faraday }}-\psi=$ $45^{\circ}$.

\section{APPENDIX II \\ NOISE COVARIANCE MATRICES}

\section{Antenna Reference Frame}

Due to the polarization mixing, the antenna temperatures at $x$ and $y$ polarizations are very similar and the radiometric sensitivity is very similar as well $\sigma^{2}=\sigma_{\mathrm{xx}}^{2}=\sigma_{\mathrm{yy}}^{2}$ [Fig. 2(a)]. Therefore, since the measurements at both polarizations are taken in different time intervals, the noise covariance matrices of the pixels in the antenna reference frame are diagonal.

- In the full-polarimetric mode: the diagonal elements are not equal, since the integration time is different for each polarization, and it is different from the odd to the even snap-shots

$$
\begin{aligned}
\overline{\overline{\mathrm{C}}}_{\text {Full-pol }}^{\text {Antenna,odd }} & =\left[\begin{array}{llll}
1 & 0 & 0 & 0 \\
0 & 3 & 0 & 0 \\
0 & 0 & 3 & 0 \\
0 & 0 & 0 & 3
\end{array}\right] \sigma^{2} \\
\overline{\overline{\mathrm{C}}}_{\text {Full-pol }}^{\text {Antenna,even }} & =\left[\begin{array}{llll}
3 & 0 & 0 & 0 \\
0 & 3 & 0 & 0 \\
0 & 0 & 3 & 0 \\
0 & 0 & 0 & 1
\end{array}\right] \sigma^{2}
\end{aligned}
$$

where the diagonal elements contain the variances of $T_{\mathrm{xx}}$, $T_{\mathrm{xy}}, T_{\mathrm{yx}}$, and $T_{\mathrm{yy}}$, respectively, and the error variance varies with the pixel position within the field of view as 
$\sigma^{2}=\sigma_{0}^{2} \cos ^{2} \theta / t^{2}(\theta, \phi)$, being $\sigma_{0}^{2}$ the variance at boresight, $t(\theta, \phi)$ the normalized antenna radiation pattern, and $\cos \theta=\sqrt{1-\xi^{2}-\eta^{2}}$ the obliquity factor.

- In the dual-polarization mode

$$
\overline{\overline{\mathrm{C}}}_{\text {Dual-pol }}^{\text {Antenna }}=\left[\begin{array}{ll}
1 & 0 \\
0 & 1
\end{array}\right] \sigma^{2}
$$

where the diagonal elements contain the noise variances of $T_{\mathrm{xx}}$ and $T_{\mathrm{yy}}$, respectively.

\section{Earth Reference Frame}

The inverse matrices of $\overline{\overline{\mathrm{M}}}_{\text {Full-pol }}$ and $\overline{\overline{\mathrm{M}}}_{\text {Dual-pol }}$ also translate the errors from the brightness temperatures measured in the antenna reference frame $\left(\Delta T_{\mathrm{xx}}, \Delta T_{\mathrm{yy}}, \Delta T_{\mathrm{xy}}\right.$, and $\left.\Delta T_{\mathrm{yx}}\right)$ to the errors in the brightness temperatures in the earth reference frame $\left(\Delta T_{\mathrm{hh}}, \Delta T_{\mathrm{vv}}, \Delta T_{\mathrm{hv}}\right.$, and $\left.\Delta T_{\mathrm{vh}}\right)$. The inverse of $\overline{\overline{\mathrm{M}}}_{\text {Full-pol }}$ is $\overline{\overline{\mathrm{M}}}_{\text {Full-pol }}^{-1}=\overline{\overline{\mathrm{M}}}_{\text {Full-pol }}$, which is never singular. However, the inverse of $\overline{\bar{M}}_{\text {Dual-pol }}$ is singular wherever $\mathrm{A}=\mathrm{B}$ $\left(\psi_{\text {Faraday }}-\psi=45^{\circ}\right)$. In the earth reference frame, the noise covariance matrices can be obtained from (A1.1) and (A2.1), or (A1.2) and (A2.2), for the full-polarimetric and dual-polarization modes, respectively.

In full-polarimetric mode: See (A2.3), shown at bottom of page. Note the following.

- In the odd and even periods, the noise variance in the brightness temperature images in the earth reference frame is not the same at horizontal polarization (element 1-1), at vertical polarization (element 4-4), and the cross-polarizations (elements 2-2 or 3-3).

- On average, in the earth reference frame, for homogeneous scenes, the radiometric sensitivity at both polarizations is the same [element 1-1 of (A2.3a) equal to element 4-4 of (A2.3b), and element 4-4 of (A2.3a) equal to element 1-1 of (A2.3b)].

- The inverse of the noise covariance matrix is never infinite.

- If the integration time for the four steps in the full-polarization mode was the same (first measurement cycle, and $\alpha-, \beta$-, and $\gamma$-modes) and equal to $2.4 \mathrm{~s} / 4=0.6 \mathrm{~s}$, the covariance matrix in the odd and even periods would be the same, and the noise covariance matrix in the antenna and in the earth reference frames would be the same

$$
\begin{aligned}
\overline{\overline{\mathrm{C}}}_{\text {Full-pol }}^{\text {Antenna,odd/even }} & \mid \\
= & {\left[\begin{array}{llll}
2 & 0 & 0 & 0 \\
0 & 2 & 0 & 0 \\
0 & 0 & 2 & 0 \\
0 & 0 & 0 & 2
\end{array}\right] \sigma^{2}=\overline{\overline{\mathrm{C}}}_{\text {Full-pol }}^{\text {earth,odd/even }} . }
\end{aligned}
$$

However, as explained in [4], this timing configuration is not feasible in SMOS, since it produces a large image blurring.

In dual-polarization mode:

$$
\overline{\overline{\mathrm{C}}}_{\text {Dual-pol }}^{\text {earth }}=\frac{1}{\left(\mathrm{~A}^{4}-\mathrm{B}^{4}\right)^{2}}\left[\begin{array}{ll}
\mathrm{A}^{4}+\mathrm{B}^{4} & -2 \mathrm{~A}^{2} \mathrm{~B}^{2} \\
-2 \mathrm{~A}^{2} \mathrm{~B}^{2} & \mathrm{~A}^{4}+\mathrm{B}^{4}
\end{array}\right] \sigma^{2} .
$$

Note the following.

- The inverse of the noise variance in the brightness temperature image in the earth reference frame is the same for both polarizations.

- The noise variance tends to infinite wherever $\mathrm{A}=\mathrm{B}$.

Fig. 8(a) and (b) shows the inverse of $\sigma$ times the square root of the elements 1-1 and 4-4 of (A2. 3a) as a function of the $(\xi, \eta)$ coordinate, that correspond to the radiometric sensitivity (except for the antenna radiation pattern and the obliquity factor) at h- or v-polarizations in an odd period, or v- or h-polarizations in an even period. Fig. 8(c) shows the squared root of the diagonal elements of $\overline{\bar{C}}_{\text {Dual-pol }}^{\text {earth }}$ (A2.5) as a function of the $(\xi, \eta)$ coordinates, that corresponds to the radiometric sensitivity (except for the antenna radiation pattern and the obliquity factor) at $\mathrm{H}$ - and $\mathrm{V}$-polarizations. Note that the radiometric sensitivity tends to infinite along a cross-liked shape, difficulting the geophysical parameter retrieval.

\section{ACKNOWLEDGMENT}

The comments and suggestions of three anonymous reviewers to improve the clarity of this work is acknowledged.

$$
\begin{gathered}
\overline{\overline{\mathrm{C}}}_{\text {Full-pol }}^{\text {earth,odd }}=\left[\begin{array}{cccc}
\mathrm{A}^{4}+6 \mathrm{~A}^{2} \mathrm{~B}^{2}+3 \mathrm{~B}^{4} & -2 \mathrm{~A}^{3} \mathrm{~B} & -2 \mathrm{~A}^{3} \mathrm{~B} & -2 \mathrm{~A}^{2} \mathrm{~B}^{2} \\
-2 \mathrm{~A}^{3} \mathrm{~B} & 3 \mathrm{~A}^{4}+4 \mathrm{~A}^{2} \mathrm{~B}^{2}+3 \mathrm{~B}^{4} & -2 \mathrm{~A}^{2} \mathrm{~B}^{2} & -2 \mathrm{AB}^{3} \\
-2 \mathrm{~A}^{3} \mathrm{~B} & -2 \mathrm{~A}^{2} \mathrm{~B}^{2} & 3 \mathrm{~A}^{4}+4 \mathrm{~A}^{2} \mathrm{~B}^{2}+3 \mathrm{~B}^{4} & -2 \mathrm{~A}^{3} \mathrm{~B} \\
-2 \mathrm{~A}^{2} \mathrm{~B}^{2} & -2 \mathrm{AB}^{3} & -2 \mathrm{AB}^{3} & 3 \mathrm{~A}^{4}+6 \mathrm{~A}^{2} \mathrm{~B}^{2}+\mathrm{B}^{4}
\end{array}\right] \sigma^{2} \\
\overline{\overline{\mathrm{C}}}_{\text {Full-pol }}^{\text {earth,even }} \\
=\left[\begin{array}{cccc}
3 \mathrm{~A}^{4}+6 \mathrm{~A}^{2} \mathrm{~B}^{2}+\mathrm{B}^{4} & -2 \mathrm{~A}^{3} \mathrm{~B} & & \\
-2 \mathrm{AB}^{3} & 3 \mathrm{~A}^{4}+4 \mathrm{~A}^{2} \mathrm{~B}^{2}+3 \mathrm{~B}^{4} & -2 \mathrm{~A}^{2} \mathrm{~B}^{2} & -2 \mathrm{~A}^{2} \mathrm{~B}^{2} \\
-2 \mathrm{AB}^{3} & -2 \mathrm{~A}^{2} \mathrm{~B}^{2} & 3 \mathrm{~A}^{4}+4 \mathrm{~A}^{2} \mathrm{~B}^{2}+3 \mathrm{~B}^{4} & -2 \mathrm{~A}^{3} \mathrm{~B} \\
-2 \mathrm{~A}^{2} \mathrm{~B}^{2} & -2 \mathrm{~A}^{3} \mathrm{~B} & -2 \mathrm{AB}^{3} \mathrm{~B} & \mathrm{~A}^{4}+6 \mathrm{~A}^{2} \mathrm{~B}^{2}+3 \mathrm{~B}^{4}
\end{array}\right] \sigma^{2}
\end{gathered}
$$




\section{REFERENCES}

[1] A. Camps, J. Bará, I. Corbella, and F. Torres, “The processing of hexagonally sampled signals with standard rectangular techniques: Application to 2-D large aperture synthesis interferometric radiometers," IEEE Trans. Geosci. Remote Sens., vol. 35, no. 1, pp. 183-190, Jan. 1997.

[2] C. S. Ruf, C. T. Swift, A. B. Tanner, and D. M. Le Vine, "Interferometric synthetic aperture microwave radiometry for the remote sensing of the earth," IEEE Trans. Geosci. Remote Sens., vol. 26, no. 5, pp. 597-611, Sep. 1988.

[3] A. Camps, J. Bará, F. Torres, and I. Corbella, "Extension of the CLEAN technique to the microwave imaging of continuous thermal sources by means of aperture synthesis radiometers," Progr. Electromagn. Res., vol. 18, pp. 67-83, Jan. 1998

[4] M. Martín-Neira, S. Ribó, and A. J. Martín-Polegre, "Polarimetric mode of MIRAS," IEEE Trans. Geosci. Remote Sens., vol. 40, no. 8, pp. 1755-1768, Aug. 2002

[5] R. Butora and A. Camps, "Noise maps in aperture synthesis radiometric images due to crosscorrelation of visibility noise," Radio Sci., vol. 38, no. 4, 1067, Jul. 23, 2003. DOI: 10.1029/2002RS002707.

[6] A. Camps, I. Corbella, F. Torres, M. Vall-llossera, and N. Duffo, "Polarimetric formulation of the visibility function equation including crosspolar antenna patterns," IEEE Geosci. Remote Sensing Lett., 2005, to be published.

[7] A. Camps et al., "Wind and Salinity Experiment 2000 (WISE 2000): Scientific analysis report," Eur. Space Res. Techol. Centre, Noordwijk, The Netherlands, ESTEC Contract 14188/00/NL/DC, Aug. 2001.

[8] S. Ribó, "Research on image validation and signal processing of aperture synthesis radiometry," Eur. Space Res. Techol. Centre, Noordwijk, The Netherlands, Int. ESTEC Working Paper 2182, Jan. 14, 2003.

[9] A. Camps, N. Duffo, M. Vall-llossera, and B. Vallespín, "Sea surface salinity retrieval using multi-angular L-band radiometry: Numerical study using the SMOS end-to-end performance simulator," in Proc. IGARSS, vol. 2, Toronto, ON, Canada, 2002, pp. 1123-1125.

[10] J. L. Miller, M. A. Goodberlet, and J. B. Zaitzeff, "Airborne salinity mapper makes debut in coastal zone," EOS Trans. AGU, vol. 79, no. 14, pp. 173-177, Apr. 7, 1998.

[11] A. Camps, J. Font, M. Vall-llossera, C. Gabarró, I. Corbella, N. Duffo, F. Torres, S. Blanch, A. Aguasca, R. Villarino, L. Enrique, J. Miranda, J. Arenas, A. Julià, J. Etcheto, V. Caselles, A. Weill, J. Boutin, S. Contardo, R. Niclós, R. Rivas, S. C. Reising, P. Wursteisen, M. Berger, and M. Martín-Neira, "The WISE 2000 and 2001 campaigns in support of the SMOS mission: Sea surface L-band brightness temperature observations and their application to multi-angular salinity retrieval," IEEE Trans. Geosci. Remote Sens., vol. 42, no. 4, pp. 804-823, Apr. 2004.

[12] C. Gabarró, J. Font, A. Camps, M. Vall-llossera, and A. Julià, "A new empirical model of sea surface microwave emissivity for salinity remote sensing," Geophys. Res. Lett., vol. 31, no. L0, 1309, 2004. DOI: 10.1029/2003GL018964.

[13] A. Camps, I. Corbella, M. Vall-llossera, R. Villarino, L. Enrique, F. Julbé, J. Font, A. Julià, C. Gabarró, J. Etchetto, J. Boutin, A. Weill, F. Torres, N. Duffo, E. Rubio, V. Caselles, P. Wursteisen, and M. Martín-Neira, "L-band sea surface emissivity: Preliminary results of the WISE-2000 campaign and its application to salinity retrieval in the SMOS mission," Radio Sci., vol. 38, no. 4, 8071, Jun. 19, 2003. DOI: 10.1029/2002RS002629.

[14] J. P. Hollinger, "Passive microwave measurements of sea surface roughness," IEEE Trans. Geosci. Electron., vol. GE-9, no. 3, pp. 165-169, May 1971.

[15] L. A. Klein and C. T. Swift, "Improved model for the dielectric constant of sea water at microwave frequencies," IEEE J. Oceanic Eng., vol. OE-2, no. 1, pp. 104-111, 1977.

[16] S. Blanch and A. Aguasca, "Seawater dielectric permittivity model from measurements at L-band," in Proc. IGARSS, vol. 2, Anchorage, AK, Sep. 2004, pp. 1362-1365.

[17] J. J. Miranda, M. Vall-llossera, A. Camps, N. Duffo, I. Corbella, and J. Etcheto, "Sea state effect on the sea surface emissivity at L-band," IEEE Trans. Geosci. Remote Sens., vol. 41, no. 10, pp. 2307-2315, Oct. 2003.

[18] W. Press, S. Teukolsky, W. Vetterling, and B. Flannery, Numerical Recipes in C. The Art of Scientific Computing, 2nd ed. Cambridge, U.K.: Cambridge Univ. Press, 1992.

[19] P. Waldteufel, N. Floury, E. P. Dinnat, and G. Caudal, "Ionospheric effects for L-band 2-D interferometric radiometry," IEEE Trans. Geosci. Remote Sens., vol. 42, no. 1, pp. 105-118, Jan. 2004.

[20] M. Pardé, J. P. Wigneron, A. Chanzy, P. Waldteufel, Y. Kerr, and S. Huet, "Retrieving surface soil moisture over a wheat field: Comparison of different methods," Remote Sens. Environ., vol. 87, no. 2-3, pp. 334-344, Oct. $15,2003$.
[21] J. P. Wigneron, P. Waldteufel, A. Chanzy, J. C. Calvet, and Y. Kerr, “Twodimensional microwave interferometer retrieval capabilities over land surfaces (SMOS mission)," Remote Sens. Environ., vol. 73, no. 3, pp. 270-282, 2000.

[22] M. Vall-llossera, A. Camps, I. Corbella, F. Torres, N. Duffo, A. Monerris, R. Sabia, D. Selva, C. Antolín, E. López-Baeza, F. Ferrer, and K Saleh, "SMOS REFLEX 2003: L-band emissivity characterization of vineyards," IEEE Trans. Geosci. Remote Sens., no. 5, May 2005.

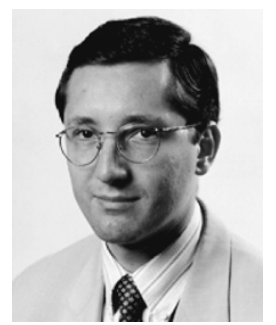

Adriano Camps (S'91-A'97-M'00-SM'02) was born in Barcelona, Spain, in 1969. He received the Telecommunications Engineering degree and the $\mathrm{Ph} . \mathrm{D}$. degree in telecommunications engineering in 1992 and 1996, respectively, both from the Polytechnic University of Catalonia (UPC), Barcelona Spain.

From 1991 to 1992, he was with the ENS des Télécommunications de Bretagne, Bretagne, France, with an Erasmus Fellowship. In 1993, he joined the Electromagnetics and Photonics Engineering group, at the Department of Signal Theory and Communications, UPC, as an Assistant Professor, and since 1997 as an Associate Professor. In 1999, he was on sabbatical leave at the Microwave Remote Sensing Laboratory, University of Massachusetts, Amherst. His research interests are microwave remote sensing, with special emphasis in microwave radiometry by aperture synthesis techniques. $\mathrm{He}$ has performed numerous studies within the frame of European Space Agency SMOS Earth Explorer Mission. He is an Associate Editor of Radio Science.

Dr. Camps received the second national award of university studies in 1993, the INDRA award of the Spanish Association of Telecommunication Engineering to the best Ph.D. in 1997, the extraordinary Ph.D. award at the Universitat Politècnica de Catalunya in 1999, the First Duran Farell Award and the Ciudad de Barcelona Award, in 2000 and 2001, respectively, both for Technology Transfer, in 2002, the Research Distinction of the Generalitat de Catalunya for contributions to microwave passive remote sensing, in 2003, the Premi Nacional de Telecomunicacions (Generalitat de Catalunya) with the members of the Electromagnetics and Photonics Engineering group, and in 2004 a EURYI (European Young Investigator) Award. Also, as a member of the Microwave Radiometry Group at UPC, he received in 2000, 2001, and 2004 the 1st Duran Farell and the Ciudad de Barcelona Awards for Technology Transfeer, and the Salvà i Campillo Award of the Telecommunications (Engineering College of Catalonia) to the most innovative research project. He was Chair of $\mathrm{Cal}$ ' 01 . He is editor of the IEEE Geoscience and Remote Sensing Newsletter and President-Founder of the IEEE Geoscience and Remote Sensing Society Spain Chapter.

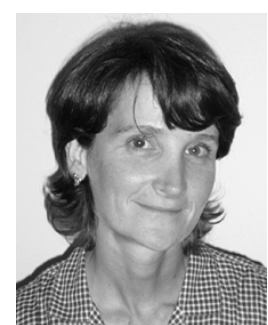

Mercè Vall-llossera (M'99) received the Senior Telecommunication Engineer and the Doctor Telecommunication Engineering degrees in 1990 and 1994, respectively, both from the Polytechnic University of Catalonia (UPC), Barcelona, Spain.

She has been lecturing and doing research at the Department of Signal Theory and Communications, UPC from 1990 until 1997 as an Assistant Professor and from 1997 until present as an Associate Professor. She spent a sabbatical year in Montreal with the scholarship of the "Programme Québécois de Bourses d'excellence" (1996-1997): "Stages de Formation postdoctorale au Québec pour jeunes diplômés étrangers." Her research interests include numerical methods in electromagnetism, microwave radiometry, antenna analysis, and design. Currently, her research is mainly related to the study of numerical methods applied to the sea surface emissivity and their characterization at L-band and the MIRAS/SMOS project.

Dr. Vall-llossera, along with the other members of the radiometry group at UPC, was awarded the "9th Edition of the Salvà i Campillo Award" in 2004, the "Primer Premio Duran Farell de Investigación Tecnológica" in 2002, and the "Primer Premio Ciutat de Barcelona d'Investigació Tecnològica" in 2001. 


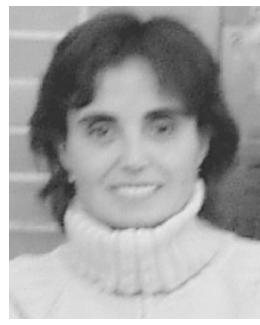

Núria Duffo (S'91-M'99) received the Telecommunication Engineer degree from the Polytechnic University of Catalonia (UPC), Barcelona, Spain, and the Doctor in Telecommunication Engineering from UPC, in 1990 and 1996, respectively.

Since 1997, she has been an Associate Professor at UPC. Her current research interests are numerical methods in electromagnetics, microwave radiometry, antenna analysis, and design.

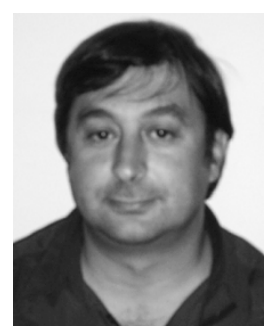

Francesc Torres (M'96) received the Ingeniero and Doctor Ingeniero degrees in telecommunication engineering from the Polytechnic University of Catalonia (UPC), Barcelona, Spain, in 1988 and 1992, respectively.

In 1988-1989, he was a Research Assistant in the RF System Division, European Space Agency, Noordwijk, The Netherlands, devoted to microwave device testing and characterization. In 1989, he joined the Antenna-Microwave-Radar group, UPC, where he is currently an Associate Professor. His main research interests are focused on the design and testing of microwave systems and subsystems. He is currently engaged in research on interferometric radiometers devoted to earth observation.

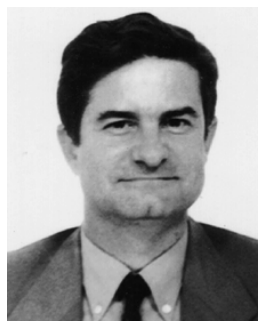

Ignasi Corbella (M'99) received the Telecommunications Engineering and Dr.Eng. degrees, both from Universitat Politècnica de Catalunya (UPC), Barcelona, Spain, in 1977 and 1983, respectively.

In 1976, he joined the School of Telecommunication Engineering in UPC as a Research Assistant in the Microwave Laboratory, where he worked on passive microwave integrated circuit design and characterization. During 1979, he worked at ThomsonCSF, Paris, France, on microwave oscillators design. In 1982, he became an Assistant Professor at UPC, an Associate Professor in 1986, and a Full Professor in 1993. He is currently teaching microwaves at the undergraduate level in UPC and has designed and taught graduate courses on nonlinear microwave circuits. During the school year 1998-1999, he worked at NOAA/Environmental Technology Laboratory, Boulder, CO, as a Guest Researcher, developing methods for radiometer calibration and data analysis. His research work in the Department of Signal Theory and Communications, UPC includes microwave airborne and satellite radiometry and microwave system design. 